\title{
A Novel Single Metal Layer MEMS-based Step-down Transformer
}

\author{
*F. Khan, Y. Zhu, J. Lu, J.Pal \\ Queensland Micro- and Nanotechnology Centre, Griffith University, QLD, 4111, Australia
}

\begin{abstract}
This paper presents for the first time single metal layer step-down on-chip transformer. The design is characterized for VHF and UHF frequency ranges. The prototype is coreless (air core), which is suitable for high frequency operations. The design is fabricated in a standard Metal-MUMPs fabrication process, which offers a single structure layer. The primary inductance of $10.7 \mathrm{nH}$ and the transformer quality factor of 8.8 have been achieved at $1 \mathrm{GHz}$. The coupling coefficient is 0.60 and the efficiency is $76 \%$ with matched load at $1 \mathrm{GHz}$. The total footprint area of microtransformer is $0.49 \mathrm{~mm}^{2}$.
\end{abstract}

\section{INTRODUCTION}

$\mathrm{T}$ he need for on-chip integration of power converters has been increased recently due to the miniaturization of portable electronics such as mobile phones, laptops, ipads etc. In order to reduce the size of dc-dc converters, switching frequency has to be increased. High switching frequency requires small inductance for regulating the output voltage therefore, transformer needs to integrated on the same silicon substrate with other electronic components.

Research work has been reported on magnetic core transformer [1-8]. However, it is difficult to introduce uniaxial anisotropy in magnetic core. Therefore, the fabrication process is fairly complex. Furthermore, losses in the magnetic core transformer is high compared to air core transformer at high frequency (>100 MHz) [7].

Air core transformers have been presented in $[9,10]$ for signal and power transfer purposes. However, the transformer windings are interleaved with turn ratio of 1:1. Thus, it can only be used in power isolation applications [11]. Similarly another air core transformer has been printed on the printed circuit board (PCB) [12]. However, the size of the transformer is too large to be called miniaturized micro-transformer. The increase in functionality and number of peripherals in portable electronics require different voltage levels, which can be achieved by using step-down or step-up transformers with various turn ratios.

In this paper, a novel single layer step-down transformer has been designed and optimized in finite element based software COMSOL, and micro-fabricated in Metal-MUMPs process.

\footnotetext{
* Corresponding author.

E-mail address: fahimullah.khan@griffithuni.edu.au,
}

The prototype is characterized using vector network analyzer and on-wafer high frequency probes. The measurement results are analyzed and discussed in experimental section.

\section{DEVICE DESIGN AND FABRICATION}

The proposed micro-transformer has a single metal layer and turn ratio of 4:2, as illustrated in Fig. 1.

The primary inductance of the symmetric transformer are given by the following equations.

$$
\begin{aligned}
L_{p} & =\frac{4.71 \times 10^{-5} \times N_{p}^{2} \times A D^{2}}{11 \times O D-14 \times A D} \\
A D & =\left(A_{o} \times A_{1} \times \ldots A_{N p-1}\right)^{1 / N p} \\
A_{i} & =\frac{O D}{2}-i \times 2 \times(W+S)
\end{aligned}
$$

where $N_{p}$ is the number of primary turns, $A D$ is the median of diameter, $O D$ is the outer diameter, $W$ is the width, and $S$ is the spacing between the turns of micro-transformer. Equation 1 illustrates that increasing diameter $O D$ can increase the primary inductance of the transformer. Similarly, primary inductance decreases by the increase in the width of the transformer conductor. Primary inductance decreases by increasing the spacing between the transformer's turns while keeping the outer diameter same.

To achieve the 4:2 ratio with high coupling coefficient, two separate secondary windings are fabricated, which are interleaved between primary windings. Bonding wires are utilized to connect the two separate secondary winding segments, and to lead out signal from the centre of the microtransformer to the outer terminals, as shown in Fig. 1.

Fig. 2 shows the SEM image of the step-down microtransformer. A $25 \mu \mathrm{m}$ air trench is made beneath the transformer structures to reduce the eddy current losses in the 
silicon substrate. To reduce the coil resistance, the microtransformer's coil is kept $50 \mu \mathrm{m}$ wide and $20.5 \mu \mathrm{m}$ thick consisting of two metal layers of nickel $(20 \mu \mathrm{m})$ and gold $(0.5$ $\mu \mathrm{m})$. The optimized design parameters of the transformer are listed in Table 1.

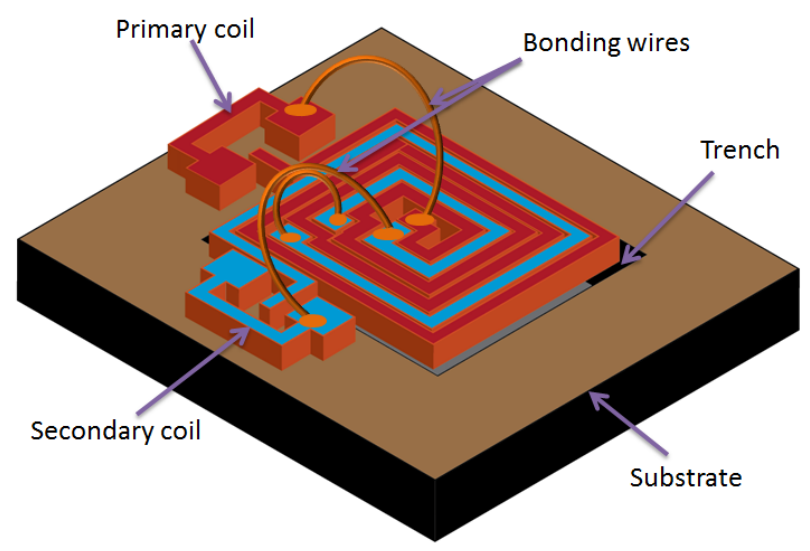

Fig. 1 Schematic layout of the step-down micro-transformer.

Table 1: Design parameters and values for the micro-transformer.

\begin{tabular}{cc}
\hline Device design parameters & Values \\
\hline Operational frequency $(\mathrm{MHz})$ & $20-1000$ \\
\hline Foot-print area $\left(\mathrm{mm}^{2}\right)$ & 0.49 \\
\hline Winding ratio & $4: 2$ \\
\hline Coil gap $(\mu \mathrm{m})$ & 6 \\
\hline Coil thickness $(\mu \mathrm{m})$ & 20.5 \\
\hline Coil width $(\mu \mathrm{m})$ & 50 \\
\hline Air trench depth $(\mu \mathrm{m})$ & 25 \\
\hline Material for core & Air \\
\hline \multirow{2}{*}{ Material for coil } & $\mathrm{Ni}(20 \mu \mathrm{m})^{+}$ \\
& $\mathrm{Au}(0.5 \mu \mathrm{m})$ \\
\hline
\end{tabular}

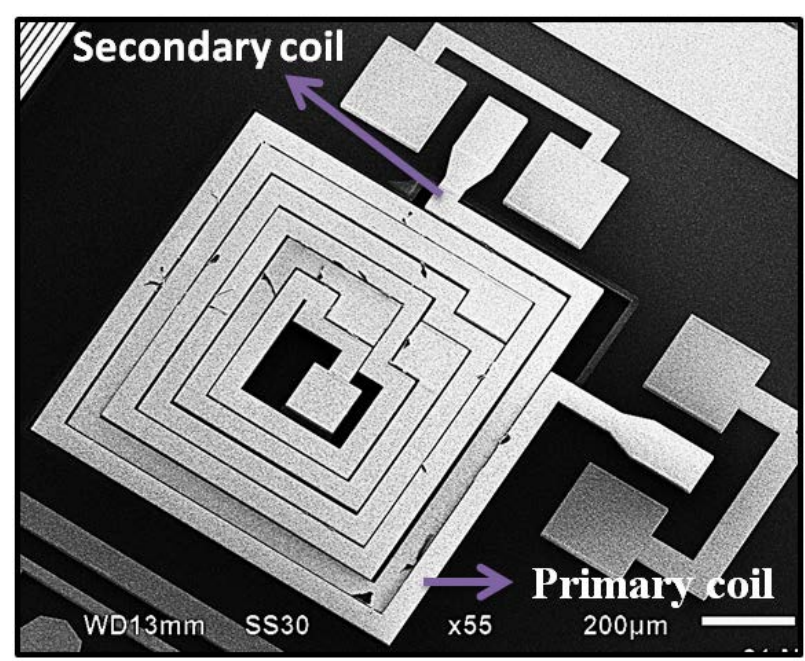

Fig. 2 SEM image of the step-down micro-transformer.

\section{EXPERIMENTAL RESULTS AND DISCUSSIONS}

The micro-transformer is characterized using Cascade Microtech's high-frequency probe station. Bonding wire connections for connecting the two segments of microtransformer, and leading out wires from the inside of transformer to the outside terminals are shown in Fig. 3. The micro-transformer's S-parameters were measured using Rohde \& Schwarz vector network analyzer. The errors in cables and probes were removed initially by short, open, through and load calibration using Agilent's on-wafer calibration tool. The Sparameters of the step-down micro-transformer were recorded from $20 \mathrm{MHz}$ to $1 \mathrm{GHz}$ and the performance parameters of the micro-transformer were extracted from S-parameters.

The measured and simulated results are illustrated in Fig. 4. As shown in Fig. 4(a), the primary inductance of $14.1 \mathrm{nH}$ was achieved experimentally at $20 \mathrm{MHz}$, and reduced to $11.8 \mathrm{nH}$ at $1 \mathrm{GHz}$. The secondary inductance of $8 \mathrm{nH}$ was measured at 10 $\mathrm{MHz}$, and decreased to $5 \mathrm{nH}$ at $1 \mathrm{GHz}$ as illustrated in Fig. 4(b). The coupling coefficient of $60 \%$ was obtained at $1 \mathrm{GHz}$ in Fig. 4(c). The reason for limited coupling factor is that transformer is air core and all of primary magnetic flux is not linking the secondary magnetic flux. Furthermore, primary coil has 4 turns and secondary has 2 turns therefore, not all of transformer's turns are interleaved. Fig. 4(d) shows the ac resistance of the primary coil, which increases linearly with the increase of frequency. It is noted from the figures that the simulated primary and secondary inductances are slightly higher than the measured results. This is due to the additional inductance of the bonding wires, which are used for interconnections between the transformer terminals.

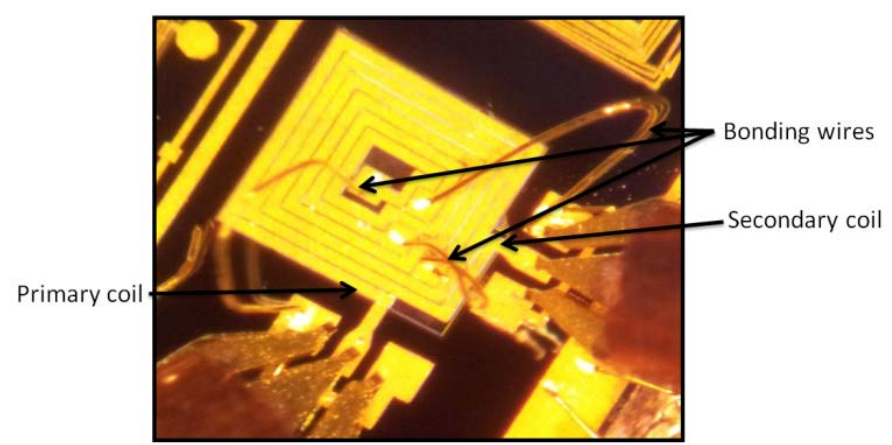

Fig. 3 Photograph of bonding wires and probe arrangements of the microtransformer. 

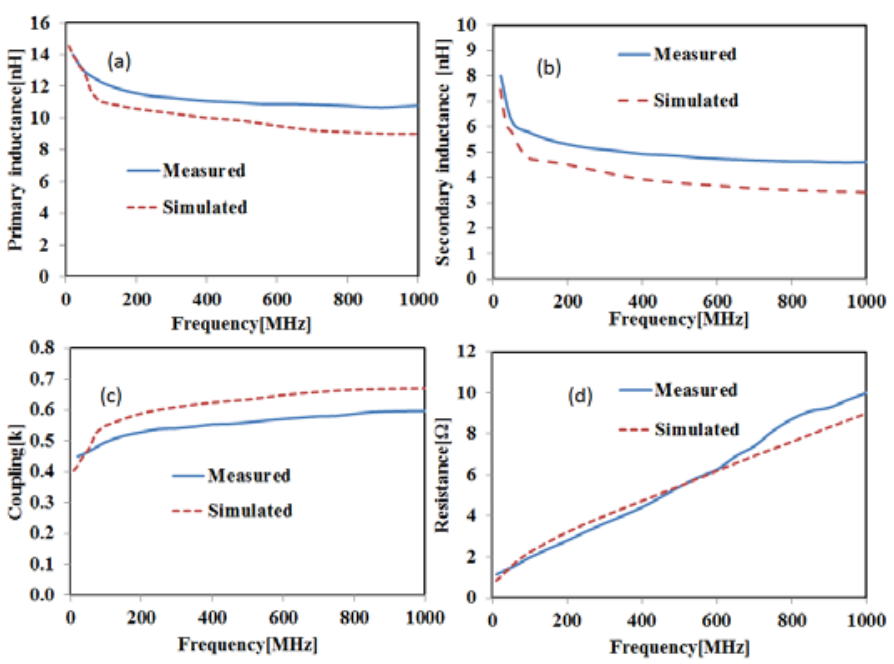

Fig. 4 Measured and simulated step-down micro-transformer parameters versus frequency.

Fig. 5 shows the quality factor of the step-down microtransformer. The quality factor increases with the increase in frequency. The maximum quality factor of 6.9 has been achieved at $1 \mathrm{GHz}$. The Q-factor can be increased by increasing width of the windings or using material with higher conductivity.

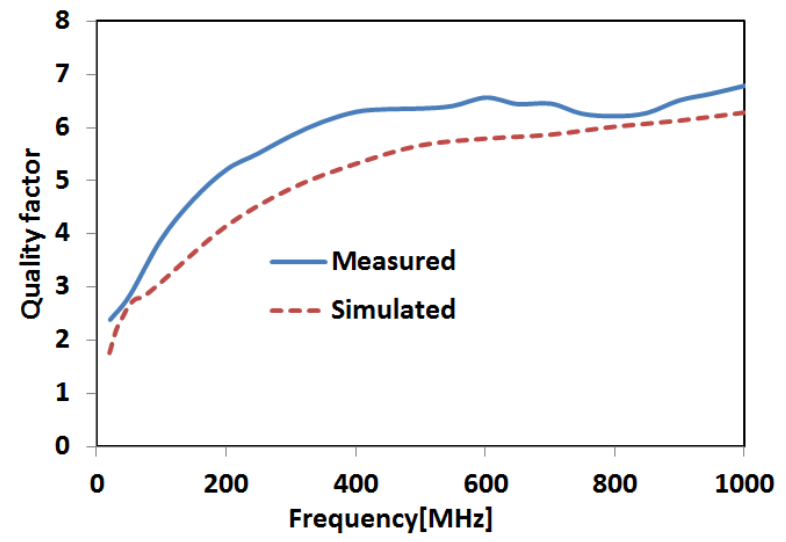

Fig. 5 Measured and simulated step-down micro-transformer Q-factor versus frequency.

Fig. 6 shows the measured voltage gain of micro-transformer versus frequency plot. The gain is low at lower frequency and increases with the increase in frequency. The lower gain is due to low mutual inductance at lower frequency. The maximum voltage gain is approximately $-4.9 \mathrm{~dB}$ at $1 \mathrm{GHz}$.

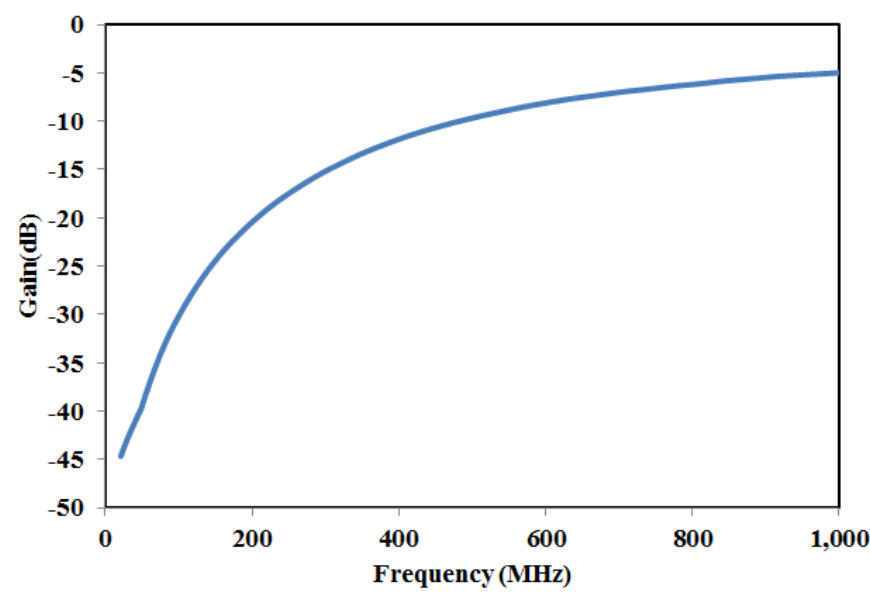

Fig. 6 Measured voltage gain at various frequencies for the step-down transformer.

The power efficiency is defined as ratio of output load power to the power incident on the transformer's primary winding. The power efficiency for $50 \Omega$ load is extracted from scattering parameters, which is given by the equation below [9].

$$
G=\frac{\left|S_{21}\right|^{2}}{1-\left|S_{11}\right|^{2}}
$$

The maximum efficiency is obtained assuming source and the load is conjugately matched to the micro-transformer, and given as [9]:

$$
G_{\max }=\frac{\left|S_{21}\right|}{\left|S_{12}\right|}\left(K-\sqrt{\left(K^{2}-1\right)}\right.
$$

where K-factor is the Rollet's stability factor defined as:

$$
K=\frac{1-\left|S_{11}\right|^{2}-\left|S_{22}\right|^{2}+\left|S_{11} S_{22}-S_{12} S_{21}\right|^{2}}{2\left|S_{12} S_{21}\right|}
$$

The efficiency of $76 \%$ has been obtained at $1 \mathrm{GHz}$ assuming source and load are matched, as shown in Fig. 7.

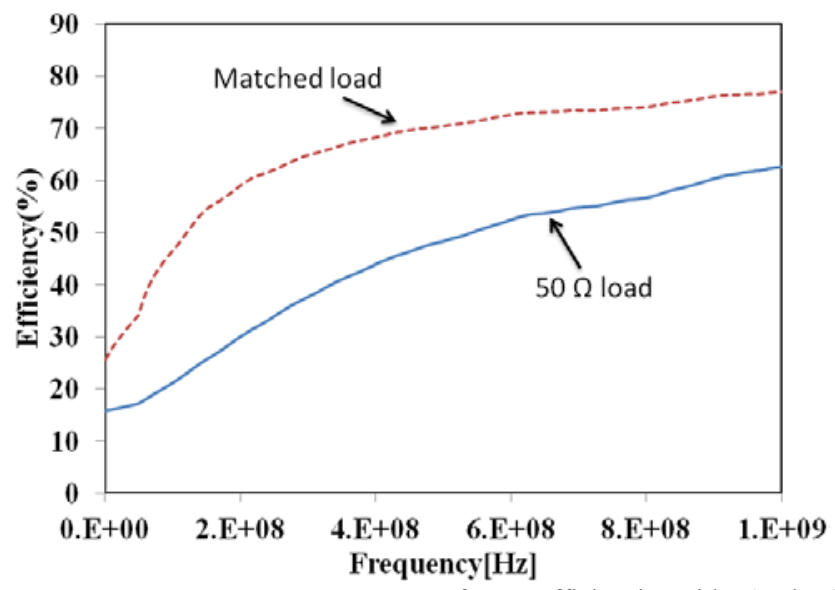

Fig. 7 Measured step-down micro-transformer efficiencies with $50 \Omega$ load and matched load. 
Table 2 listed the measured parameters and values of the microtransformer. The maximum Q-factor of the step-down microtransformer is approximately 8.8 at $1 \mathrm{GHz}$.

Table 2: Device parameters and values extracted from S-parameters

\begin{tabular}{cc}
\hline Device parameters & Parameters values \\
\hline Primary inductance @1GHz $(\mathrm{nH})$ & 10.7 \\
\hline Secondary inductance @1GHz $(\mathrm{nH})$ & 4.6 \\
\hline DC resistance $(\Omega)$ & 0.32 \\
\hline Coupling coefficient & 0.60 \\
\hline Max. Q-factor & 6.9 \\
\hline Frequency of max. Q-factor $(\mathrm{MHz})$ & 1000 \\
\hline Max. Efficiency, $\mathrm{G}_{\max }(\%)$ & 76 \\
\hline Frequency of max. efficiency $(\mathrm{MHz})$ & 1000 \\
\hline Resonance frequency $(\mathrm{GHz})$ & 5.55 \\
\hline
\end{tabular}

Table 3 shows the comparison of the recent work on the microtransformers. It is noted that the PCB micro-transformer achieved high efficiency but has a large foot-print area. The micro-transformers with 1:1 turn ratio also have better efficiencies but cannot provide voltage conversion. The proposed step-down micro-transformer provides voltage conversion and has small foot-print area.

Table 3: Comparison of state of the art micro-transformers

\begin{tabular}{|c|c|c|c|c|c|c|}
\hline & $\begin{array}{c}\text { Kotte } \\
2013 \\
{[13]}\end{array}$ & $\begin{array}{c}\text { Majid } \\
2011 \\
{[14]}\end{array}$ & $\begin{array}{l}\text { Wang } \\
2012 \\
{[15]}\end{array}$ & $\begin{array}{c}\text { Wu } \\
2015 \\
{[16]}\end{array}$ & $\begin{array}{l}\text { Khan } \\
2015 \\
{[17]}\end{array}$ & This Work \\
\hline Magnetic Core & No & No & Yes & No & No & No \\
\hline Turn ratio & $4: 1$ & $4: 1$ & $1: 1$ & $1: 1$ & $1: 1$ & $2: 1$ \\
\hline No. of masks & PCB & PCB & 7 & 3 & 3 & 3 \\
\hline No. of metal layers & 4 & 4 & 1 & 1 & 1 & 1 \\
\hline Cross-overs/Vias & Yes & Yes & No & No & No & No \\
\hline Area(mm2) & 1575 & NA & 3 & 2.0 & 1.76 & 0.49 \\
\hline Frequency(MHz) & $2-4$ & $1-6$ & 20 & 20 & $20-1000$ & $20-1000$ \\
\hline Primary inductance & $6-8 \mu \mathrm{H}$ & $\begin{array}{c}.73 @ 1 \mathrm{M} \\
\mathrm{Hz}\end{array}$ & 1210 & 88 & 7.14@500MHz & $\begin{array}{c}10.7 \\
\mathrm{nH} @ 1 \mathrm{GHz}\end{array}$ \\
\hline Dc Resistance $(\Omega)$ & 0.52 & NA & 1.0 & 0.45 & 0.44 & 0.32 \\
\hline Coupling & NA & NA & 0.97 & 0.98 & 0.75 & 0.60 \\
\hline Efficiency & 92 & 93.5 & $75 \%$ & $80 \%$ & $68 \%$ & $76 \%$ \\
\hline
\end{tabular}

\section{CONCLUSION}

A novel MEMS-based step-down transformer has been proposed and characterized. The micro-transformer is optimized through finite element based software COMSOL. The advantage of this type of step-down transformer is that only single metal layer is utilized, which reduces the overall fabrication cost and complexity. The prototype is implemented in Metal-MUMPs fabrication process. Bonding wires have been used to connect the two segments of secondary coils and to lead out the inner terminals of micro-transformer to the outer terminals. The efficiency of $76 \%$ has been achieved for matched load at $1 \mathrm{GHz}$. The micro-transformer is suitable for on-chip single layer integrated power supplies.

\section{ACKNOWLEDGEMENT}

This work was performed in part at the Queensland Node of the Australian National Fabrication Facility.

\section{REFERENCES}

[1] H. Kurata, K. Shirakawa, O. Nakazima, and K. Murakami, "Study of thin film micro transformer with high operating frequency and coupling coefficient," IEEE Transactions on Magnetics, vol. 29, pp. 3204-3206, 1993.

[2] A. Lotfi, R. B. van Dover, L. Schneemeyer, and M. Steigerwald, "Micro-transformer devices using thin-film electroplated deposition," in Power Electronics Specialists Conference, 1998. PESC 98 Record. 29th Annual IEEE, 1998, pp. 1511-1515.

[3] M. Xu, T. M. Liakopoulos, C. H. Ahn, S. H. Han, and H. J. Kim, "A microfabricated transformer for high-frequency power or signal conversion," IEEE Transactions on Magnetics, vol. 34, pp. 1369-1371, 1998.

[4] T. M. Liakopoulos and C. H. Ahn, "3-D microfabricated toroidal planar inductors with different magnetic core schemes for MEMS and power electronic applications," Magnetics, IEEE Transactions on, vol. 35, pp. 3679-3681, 1999.

[5] M. Brunet, T. O'Donnell, J. O'Brien, P. McCloskey, and C. O'Mathuna, "Design study and fabrication techniques for high power density microtransformers," in Applied Power Electronics Conference and Exposition, 2001. APEC 2001. Sixteenth Annual IEEE, 2001, pp. 11891195.

[6] C. Ó. Mathúna, N. Wang, S. Kulkarni, and S. Roy, "Review of integrated magnetics for power supply on chip (PwrSoC)," Power Electronics, IEEE Transactions on, vol. 27, pp. 4799-4816, 2012.

[7] R. Meere, N. Wang, T. O'Donnell, S. Kulkarni, S. Roy, and S. C. O'Mathuna, "Magnetic-core and air-core inductors on silicon: A performance comparison up to $100 \mathrm{MHz}, "$ Magnetics, IEEE Transactions., vol. 47, pp. 4429-4432, 2011.

[8] L. Zheng, H. Qin, J. Xu, J. Hu, J. Liu, and L. Ye, "Influence of ferrite thin-film layer on property of stacked spiral thin-film transformer," 2007. [9] C. D. Meyer, S. S. Bedair, B. C. Morgan, and D. P. Arnold, "Highinductance-density, air-core, power inductors, and transformers designed for operation at 100-500 MHz," Magnetics, IEEE Transactions on, vol. 46, pp. 2236-2239, 2010.

[10] B. Kang, C. Park, and S. Chung, "Integrated transformer using magnetic sheet for LLC resonant converter," Electronics Letters, vol. 50, pp. 770-771, 2014.

[11] B. Chen, "Fully integrated isolated dc-dc converter using microtransformers," in Applied Power Electronics Conference and Exposition, 2008. APEC 2008. Twenty-Third Annual IEEE, 2008, pp. 335-338.

[12] S. Tang, S. Hui, and H. Chung, "Coreless printed circuit board (PCB) transformers with high power density and high efficiency," Electronics Letters, vol. 36, pp. 943-944, 2000.

[13] H. B. Kotte, R. Ambatipudi, and K. Bertilsson, "High-speed (MHz) series resonant converter (SRC) using multilayered coreless printed circuit board (PCB) step-down power transformer," Power Electronics, IEEE Transactions on, vol. 28, pp. 1253-1264, 2013.

[14] A. Majid, H. B. Kotte, J. Saleem, R. Ambatipudi, S. Haller, and K. Bertilsson, "High frequency half-bridge converter using multilayered coreless Printed Circuit Board step-down power transformer," in Power Electronics and ECCE Asia (ICPE \& ECCE), 2011 IEEE 8th International Conference on, 2011, pp. 1177-1181.

[15] N. Wang, S. Kulkarni, B. Jamieson, J. Rohan, D. Casey, S. Roy, et al., "High efficiency Si integrated micro-transformers using stacked copper windings for power conversion applications," in Applied Power Electronics Conference and Exposition (APEC), 2012 Twenty-Seventh Annual IEEE, 2012, pp. 411-416.

[16] R. Wu, N. Liao, X. Fang, and J. K. Sin, "A Silicon-Embedded Transformer for High-Efficiency, High-Isolation, and Low-Frequency OnChip Power Transfer," 2015.

[17] F. Khan, Y. Zhu, J. Lu, J. Pal, and D. V. Dao, "Micromachined Coreless Single-Layer Transformer Without Crossovers," Magnetics Letters, IEEE, vol. 6, pp. 1-4, 2015. 